\title{
One-Step Fabrication of Methylthiazole-Functionalized Anion Exchange Membranes for Diffusion Dialysis
}

\author{
Hong Hu*, Wei Song \\ School of Biology and Environment, Nanjing Polytechnic Institute, Nanjing, China \\ Email: ^hhu@njpi.edu.cn
}

How to cite this paper: $\mathrm{Hu}, \mathrm{H}$. and Song, W. (2018) One-Step Fabrication of Methylthiazole-Functionalized Anion Exchange Membranes for Diffusion Dialysis. Open Journal of Physical Chemistry, 8, 100-109. https://doi.org/10.4236/ojpc.2018.84007

Received: November 20, 2018

Accepted: November 27, 2018

Published: November 30, 2018

Copyright ( 92018 by authors and Scientific Research Publishing Inc. This work is licensed under the Creative Commons Attribution International License (CC BY 4.0).

http://creativecommons.org/licenses/by/4.0/

\section{c) (i) Open Access}

\begin{abstract}
Anion exchange membranes using brominated poly(2,6-dimethyl-1,4-phenylene oxide) (BPPO) as starting material were prepared from one-step functionalization by 4-methylthiazole (MTz). The obtain membranes with high thermal stability and mechanical strength showed satisfied diffusion dialysis performance for acid recovery. Specifically, when the optimal membrane was evaluated to recover acid from the simulated iron polishing waste solution (1.0 $\left.\mathrm{mol} \cdot \mathrm{L}^{-1} \mathrm{FeCl}_{2}+0.2 \mathrm{~mol} \cdot \mathrm{L}^{-1} \mathrm{HCl}\right)$, its acid diffusion coefficient $\left(\mathrm{U}_{\mathrm{H}+}\right)$ was 0.019 $\mathrm{m} \mathrm{h}^{-1}$ and separation factor was 40.1 at $25^{\circ} \mathrm{C}$, both of these two parameters are much higher than the corresponding values of the commercial DF-120 membrane, suggesting the great potential in the practical application for acid recovery.
\end{abstract}

\section{Keywords}

Diffusion Dialysis, Anion Exchange Membrane, Acid Recovery, Methylthiazole

\section{Introduction}

Diffusion dialysis (DD) employing anion exchange membrane (AEM) as core component is recognized as the most economically promising technology for acid recovery from the industrial waste water, such as metal etching, titanium white production, stripping processes and so on [1] [2] [3] [4] [5]. It is well known that AEM has a positively charged matrix, such chemical structure may allow anions in the acidic waste solution (e.g. $\mathrm{Cl}^{-}, \mathrm{NO}_{3}^{-}, \mathrm{SO}_{4}^{2-}$ ) to firstly permeate through AEM and then permeate into the side with lower concentration 
(always water) because of the electrostatic attraction, and then cations (e.g. $\mathrm{H}^{+}$ and metal ions) should then permeate into the side with lower concentration to fulfill the requirement of the electric neutrality [6]. Notably, such DD process is spontaneous and the driving force is only from the concentration gradient between the feed and permeate side. Therefore, DD technic reveals many advantages, especially the low economic cost and great environmental benefits, as compared with other separation processes [7] [8] [9]. Obviously, the permeate rate of proton will directly decide the acid recovery rate and the ratio of permeate rate between proton and metal ions will decide the purity of the recovered acid. The two above-mentioned parameters are designed as acid diffusion coefficient $(U)$ and separation factor $(S)$.

Obviously, AEMs are the critical component for the DD module. They are required to possess high ion permeability, good thermal and chemical stabilities, proper water uptake and low swelling ratio. It was found that the recent research mainly focused on the polymer chains of AEMs [10]-[15], and the investigation on the functional group for ion exchange is rare. Moreover, among the AEMs used in $\mathrm{DD}$, they are always bearing quaternary ammonium groups as ion exchange groups. It is noted that there are some drawbacks of quaternary ammonium functional groups. Such as unsatisfied thermal stability and low ion permeability compared with other ion exchange groups [16]. In order to enhance the thermal stability and the ion permeability, as well as to extent the variety of the ion exchange groups, other functional agent being able to offer the newly ion exchange groups should be investigated. 4-methylthiazole (MTz) is a nucleophilic agent that has a high reaction activity, also its alkalinity (pKa 30.3) is much higher than trimethylamine ( $\mathrm{pKa} \mathrm{10.8)} \mathrm{as} \mathrm{the} \mathrm{procedure} \mathrm{of} \mathrm{quaternary}$ ammonium groups. Therefore, compared with quaternary ammonium groups, methylthiazolium from MTz should endow the obtained membrane with much higher ion permeability [16]. To our best knowledge, methylthiazole as he functional reagent for the preparation of AEMs for DD has not been investigated. Therefore, in this paper, 4-methylthiazole was selected for the functionalization of AEMs. Moreover, bromiated poly(2,6-dimethyl-1,4-phenylene oxide) (BPPO) with excellent mechanical properties and good membrane forming ability was selected as the polymer backbone. Because of the high reactivity between $\mathrm{MTz}$ and $-\mathrm{CH}_{2} \mathrm{Br}$ groups of BPPO, the reaction between them can be easily carried out to get the MTz-PPO AEMs via one-step reaction.

Specifically, the main purpose of this work is to prepare AEMs with high diffusion dialysis performance based on BPPO. The fabrication process will be investigated in detail and the chemical structure of the obtained AEMs will be conducted. The diffusion dialysis-related properties like ion exchange capacity (IEC), water uptake ( $W U$ ) and swelling ratio will also be investigated. More important, the DD performance of the obtained AEMs will be evaluated using the simulated acidic waste solution composing of $1 \mathrm{~mol} \cdot \mathrm{L}^{-1} \mathrm{HCl}$ and $0.2 \mathrm{~mol} \cdot \mathrm{L}^{-1}$ $\mathrm{FeCl}_{2}$. 


\section{Experimental}

\subsection{Materials}

Brominated poly(2,6-dimethyl-1,4-phenylene oxide) (BPPO) with benzyl bromination degree of 0.57 and aryl bromination degree of 0.43 was kindly provided by Tianwei Membrane Company (Shandong, PR China). 4-methylthiazole (MTz, AR) was purchased from ALADDIN Chemical Co., Ltd. (Shanghai, PR China). The other chemicals were used as received without further purification.

\subsection{Synthesis of MTz-PPO-x}

MTz-PPO AEMs were fabricated by one-step reaction between BPPO and MTz. Firstly, $2 \mathrm{~g}$ BPPO was dissolved in $18 \mathrm{~g}$ NMP to form a homogenous solution, a certain amount of MTz was added dropwise into the BPPO/NMP solution. The solution was firstly stirred for $12 \mathrm{~h}$ at $60^{\circ} \mathrm{C}$ and then stirred at $90^{\circ} \mathrm{C}$ for $6 \mathrm{~h}$. Finally, the solution was poured into ethanol to get the brown precipitate, which was collected and washed with water, followed by drying in an oven for $12 \mathrm{~h}$ at $50^{\circ} \mathrm{C}$. Then the precipitate was re-dissolved in NMP to form a $10 \mathrm{wt} \%$ solution and then casted onto a pre-cleaned glasses, which would be dried in an oven at $60^{\circ} \mathrm{C}$ for $12 \mathrm{~h}$ to get the MTz-PPO embranes. The ratios of BPPO and MTz were set as 1:0.2, 1:0.4, 1:0.6, 1:0.8 and 1:1.1, respectively, the corresponding obtained AEMs were then correspondingly denoted as MTz-PPO-1, MTz-PPO-2 MTz-PPO-3, MTz-PPO-4, MTz-PPO-5 membrane, respectively.

\subsection{Characterization}

Fourier Transform Infrared Spectroscopy (FTIR) spectra were measured using a Vector 22 Fourier transform infrared spectrometer (Bruker). The thermogravimetric analysis was performed by a Q5000 thermo gravimetric analyzer (TGA, TA Instruments). Mechanical properties of the membranes were measured by a Q800 dynamic mechanical analyzer (DMA, TA Instruments).

Ion exchange capacity (IEC) with respect to the density of the ion exchange groups (mmol. $\mathrm{g}^{-1}$ ) was measured by the conventional Mohr method. A dried membrane was immersed into a $0.1 \mathrm{~mol} \cdot \mathrm{L}^{-1} \mathrm{NaOH}$ at room temperature for 12 $\mathrm{h}$, after thoroughly washed with water, the membrane was then immersed in 1 $\mathrm{mol} \cdot \mathrm{L}^{-1} \mathrm{NaCl}$ solution for $24 \mathrm{~h}$ at room temperature. Finally, the solution was titrated with ca. $0.05 \mathrm{~mol} \cdot \mathrm{L}^{-1} \mathrm{Na}_{2} \mathrm{CO}_{3}$ solution using methyl orange as an indicator. IEC then can be calculated as follows:

$$
\mathrm{IEC}=\frac{C_{\mathrm{Na}_{2} \mathrm{CO}_{3}} \times V_{\mathrm{Na}_{2} \mathrm{CO}_{3}}}{W_{\text {dry }}},
$$

where $C_{\mathrm{Na}_{2} \mathrm{CO}_{3}}$ and $V_{\mathrm{Na}_{2} \mathrm{CO}_{3}}$ are the concentration and the consumed volume of $\mathrm{Na}_{2} \mathrm{CO}_{3}$ solution, and $W_{\text {dry }}$ is the dry weight of the membrane.

Water uptake $(W U)$ and swelling ratio refer to the respective weight and length change after fully hydration. Specifically, the dry membrane was weighted and its length was measured, then it was immersed in water at room tempera- 
ture for $48 \mathrm{~h}$. After that, its weight and length was measured. Water uptake and Swelling ratio can be calculated as follow:

$$
\begin{gathered}
W U=\frac{W_{\text {wet }}-W_{\text {dry }}}{W_{\text {dry }}} \times 100 \% ; \\
\text { Swelling ratio }=\frac{L_{\text {wet }}-L_{\text {dry }}}{L_{\text {dry }}} \times 100 \%
\end{gathered}
$$

where $W_{\text {dry }}$ and $W_{\text {wet }}$ are the dry and wet weights of the membrane, respectively, and $L_{\text {dry }}$ and $L_{\text {wet }}$ are the dry and wet lengths of the membrane.

Diffusion dialysis (DD) test was conducted according to the previously reported method [6]. The membrane sample was firstly immersed in the simulated iron polishing waste solution $\left(1 \mathrm{~mol} \cdot \mathrm{L}^{-1} \mathrm{HCl}+0.2 \mathrm{~mol} \cdot \mathrm{L}^{-1} \mathrm{FeCl}_{2}\right)$ for $12 \mathrm{~h}$, and then thoroughly washed with water. It was then fixed between 2 compartment cells with an overlapped circular hole, whose effective area is $5.42 \mathrm{~cm}^{-2}$. The feed and permeate sides were then filled with $100 \mathrm{ml}$ above mentioned simulated solution and $100 \mathrm{ml}$ water, respectively. The stirring was initiated to start the test at room temperature, after $45 \mathrm{~min}$, the stirring was stopped. The concentrations of $\mathrm{HCl}$ and $\mathrm{FeCl}_{2}$ in both feed and permeate sides were measured by titration. Specially, the $0.05 \mathrm{~mol} \cdot \mathrm{L}^{-1} \mathrm{Na}_{2} \mathrm{CO}_{3}$ solution and methyl orange solution were respectively used as titrant and indicator for the measurement of $\mathrm{HCl}$ concentration, while $0.001 \mathrm{~mol} \cdot \mathrm{L}^{-1} \mathrm{KMnO} 4$ solution was used as simultaneous titrant and indicator for the measurement of $\mathrm{FeCl}_{2}$ concentration.

Separation factor $(S)$ is calculated as the ratio of dialysis coefficients $(U)$ of $\mathrm{HCl}$ and $\mathrm{FeCl}_{2}$. Dialysis coefficient $(U)$ of $\mathrm{HCl}$ or $\mathrm{FeCl}_{2}$ is defined as follows:

$$
U=\frac{M}{A t \triangle C} ;
$$

where $M$ (mole) is the amount of ions transported into the permeate side, $A\left(\mathrm{~m}^{2}\right)$ is the effective area between two cells, $t(\mathrm{~h})$ is the diffusion time. $\Delta C\left(\mathrm{~mol} \cdot \mathrm{L}^{-1}\right)$ is the logarithm average concentration difference between feed and permeate sides.

$$
\Delta C=\frac{C_{f}^{0}-\left(C_{f}^{t}-C_{d}^{t}\right)}{\ln \left[C_{f}^{0} /\left(C_{f}^{t}-C_{d}^{t}\right)\right]}
$$

where $C_{f}^{0}$ and $C_{f}^{t}$ are the concentration of $\mathrm{HCl}$ or $\mathrm{FeCl}_{2}$ in the feed side before and after test, $C_{d}^{t}$ is the concentration of $\mathrm{HCl}$ or $\mathrm{FeCl}_{2}$ in the permeate side after test.

\section{Results and Discussion}

As mentioned above, MTz-PPO AEMs were synthesized via facile one-step reaction. The final obtained membranes are uniform, transparent and mechanically strong (See Figure 1). What is more important, their thickness and shape can be easily controlled.

FT-IR analysis can be used to identify the presence of the functional groups as well as the chemical composition of the membranes. As shown in Figure 2, the 


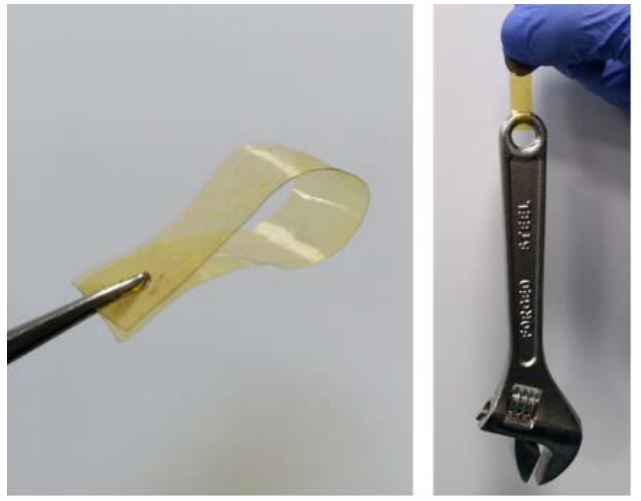

Figure 1. Photographs of the MTz-PPO-5 membrane. $(\mathrm{ca} .1 \mathrm{~cm} \times 4 \mathrm{~cm}$, thickness $=\mathrm{ca} .60$ $\mu \mathrm{m})$.

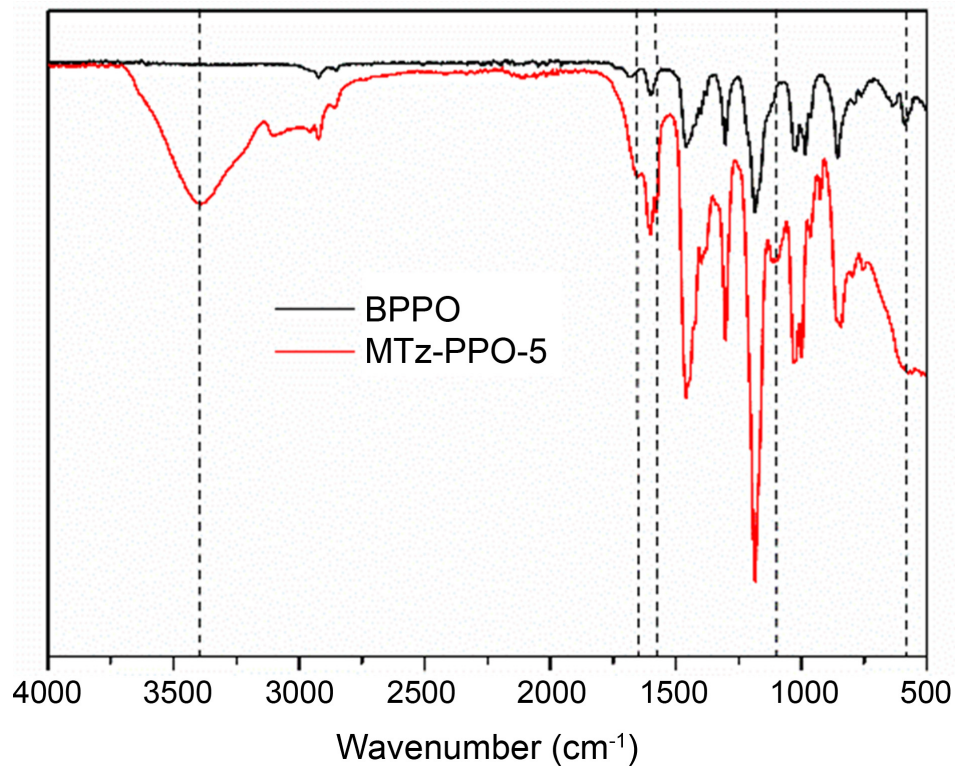

Figure 2. FT-IR spectra of BPPO and MTz-PPO-5 membranes.

spectrum of BPPO membrane has a characteristic band at ca. $588 \mathrm{~cm}^{-1}$, attributing to the C-Br stretching [17]. By contrast, the selected MTz-PPO-5 membranes displays a characteristic band at ca. $3395 \mathrm{~cm}^{-1}$, attributing to the $-\mathrm{OH}$ stretching from the adsorbed water molecules [18]. It also displays two characteristic bands at $1663 \mathrm{~cm}^{-1}$ and $1578 \mathrm{~cm}^{-1}$, corresponding to the stretching of $\mathrm{C}=\mathrm{N}$ and $\mathrm{C}-\mathrm{N}$ groups [19], respectively. Besides, one newly formed characteristic band at ca. $1100 \mathrm{~cm}^{-1}$ can be clearly observed for the spectrum of MTz-PPO-5, suggesting the formation of the positively charged quaternary ammonium groups, which play the key role for the ion transport [20]. Moreover, from BPPO to MTz-PPO-5, the characteristic band at $588 \mathrm{~cm}^{-1}$ disappears, indicating the fully consumption of $\mathrm{C}-\mathrm{Br}$ after reaction. This results mean that the reaction activity between BPPO and $\mathrm{MTz}$ was high and the functional degree of BPPO polymer can be optimized.

TGA test was used to determine the thermal stability of the obtained MTz-PPO 
AEMs and the MTz-PPO-5 AEM was selected. As can be seen in Figure 3, BPPO membrane starts to degrade at $250^{\circ} \mathrm{C}$, suggesting that $\mathrm{BPPO}$ is an excellent starting material because of the good thermal stability. Therefore, MTz-PPO-5 membrane with the similar polymer chain also possesses good thermal stability, and its starting degradation temperature is about $175^{\circ} \mathrm{C}$, due to the thermal degradation of the charged thiazolium rings, which is also higher than that of quaternary ammonium groups (ca. $140^{\circ} \mathrm{C}$ ) [21]. That is because of the presence of the resonance structure, improving the stability of the ion exchange groups. Such results are satisfied and the thermal stability of the obtained AEMs can meet the requirement of the practical application.

The IEC values of the MTz-PPO AEMs are shown in Figure 4. From MTz-PPO-1 AEM to MTz-PPO-5 AEM, the IEC values increase from 0.48 to $2.07 \mathrm{mmol} \cdot \mathrm{g}^{-1}$. It is noted that the IEC value was determined by the amount of the ion exchange groups, which was formed by the reaction between $-\mathrm{CH}_{2} \mathrm{Br}$ groups of BPPO polymer and MTz, because that the amount of BPPO was fixed, the ratio of the amount of $\mathrm{MTzto}-\mathrm{CH}_{2} \mathrm{Br}$ will directly decide the functional degree as well as the amount of quaternary ammonium groups [22]. From MTz-PPO-1 to MTz-PPO-5 membrane, the ratio of $\mathrm{MTz}$ to $-\mathrm{CH}_{2} \mathrm{Br}$ increases from $20 \%$ to $100 \%$, so it is easy to understand the increasing tendency of the IEC value of MTz-PPO AEMs.

Figure 5 shows the values of water uptake and swelling ratio of the MTz-PPO AEMs. These AEMs have a water uptake ( $W U$ ) of 5.5\% - 42.5\%, and a swelling ratio of $3.1 \%-18.6 \%$. Moreover, the values of water uptake and swelling ratio also show an increasing trend similar to that of IEC. This is because that the reaction between BPPO and MTz will introduce the charged methylthiazolium groups, which are hydrophilic and are in favor of water adsorption. The hydrophilicity would soft the polymer chain and increase the free space of the polymer, as

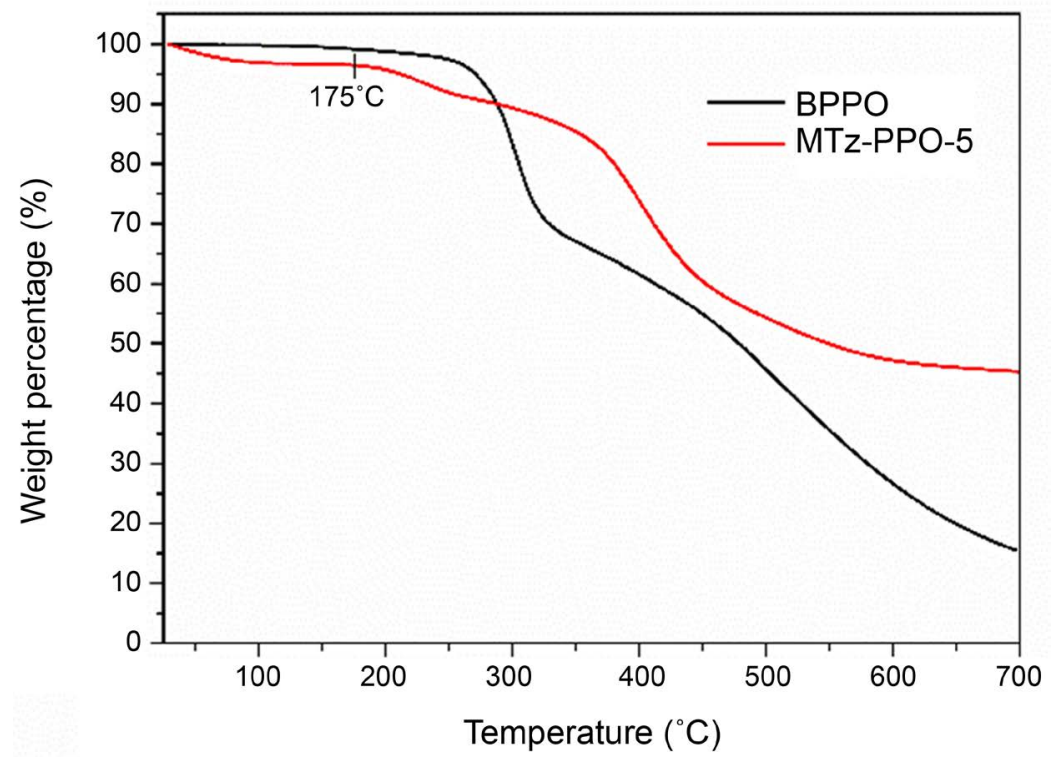

Figure 3. TGA curves of BPPO and MTz-PPO-5 membranes. 


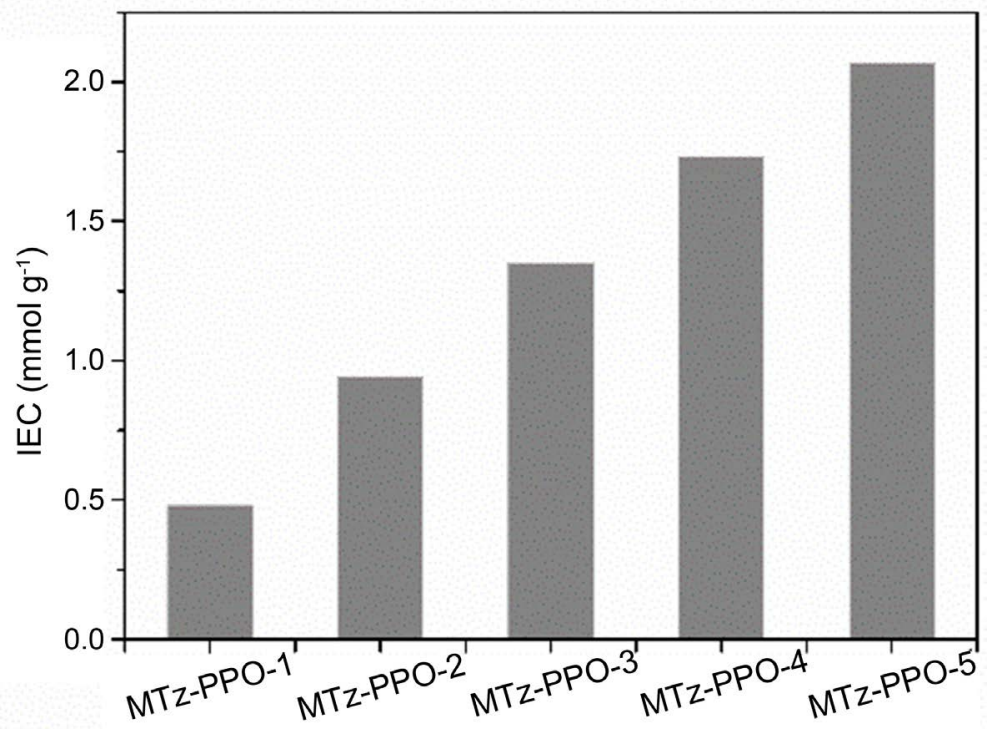

Figure 4. IEC values of MTz-PPO AEMs.

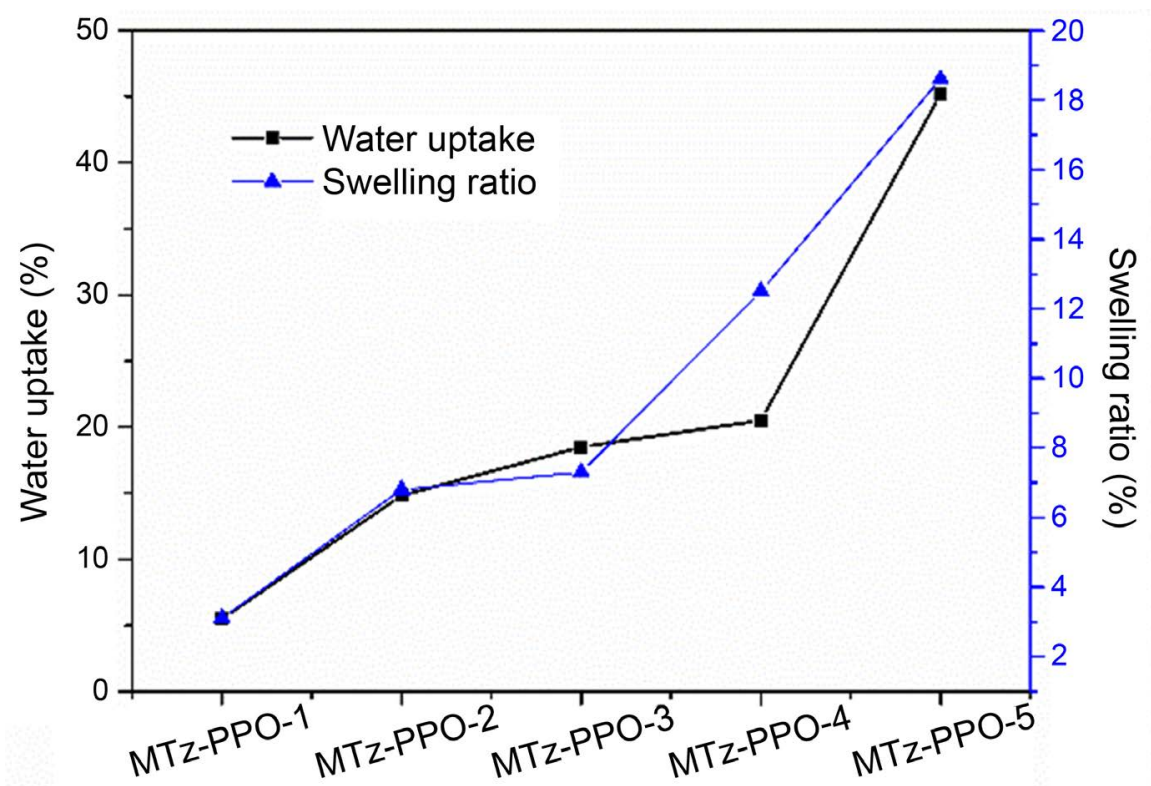

Figure 5. Water uptake and swelling ratio values of MTz-PPO AEMs.

a result, the swelling ratio will also increase. In one word, the increasing hydrophilicity should play a positive role on water uptake and swelling ratio of the membranes. So the increasing trends of water uptake and swelling ratio from MTz-PPO- 1 to MTz-PPO-5 are easily to be understood.

Figure 6 shows the diffusion dialysis properties of the MTz-PPO membrane, when they were used to recovery acid from the simulated acidic waste solution. It was found that from MTz-PPO-1 membrane to MTz-PPO-5 membrane, the acid diffusion coefficient $\left(\mathrm{U}_{\mathrm{H}+}\right)$ and salt diffusion coefficient $\left(\mathrm{U}_{\mathrm{Fe} 2+}\right)$ were increased from 0.005 to $0.019 \mathrm{~m} \cdot \mathrm{h}^{-1}$ and from 0.00008 to $0.0004 \mathrm{~m} \cdot \mathrm{h}^{-1}$ at $25^{\circ} \mathrm{C}$ respectively. These results are due to the increasing IEC and $W U$ of the membranes 


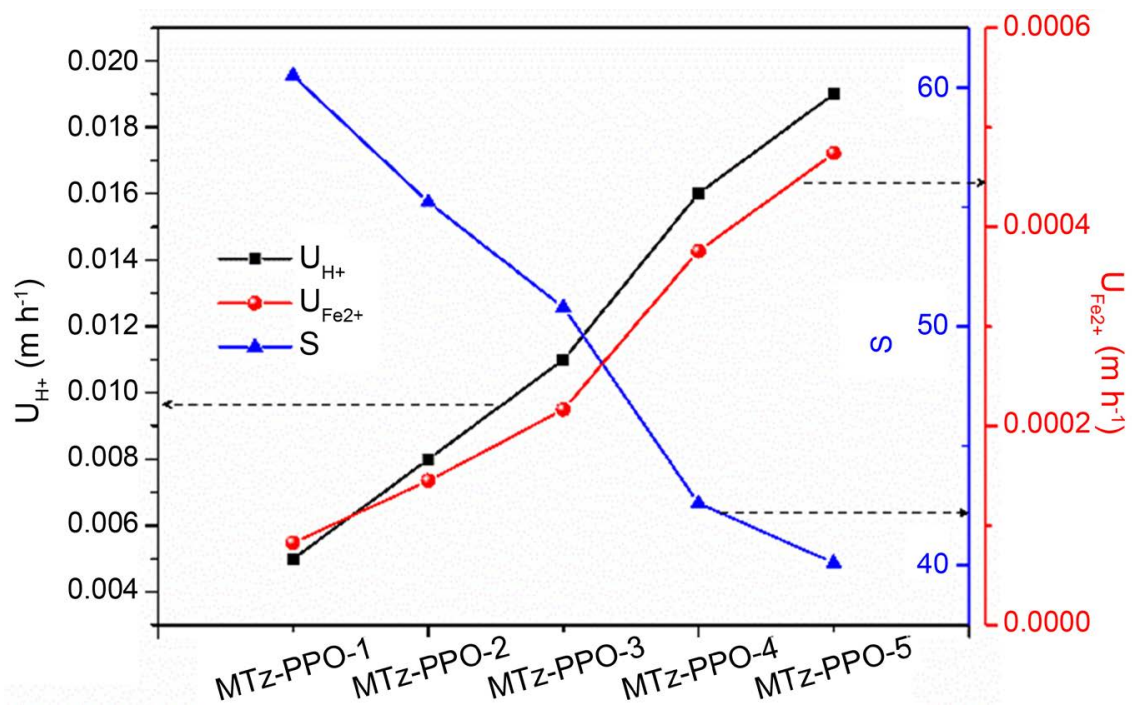

Figure 6. Diffusion dialysis performance of MTz-PPO AEMs being used in the acid recovery from the simulated waste solution at $25^{\circ} \mathrm{C}$.

from MTz-PPO-1 to MTz-PPO-5, promoting the ion transport because of the increasing amount of ion exchange site and the free space volume. It seems that the effect of the enhanced IEC and $W U$ on the acceleration of the ion transport by is much more remarkable for salt $\left(\mathrm{FeCl}_{2}\right)$ rather than acid $(\mathrm{HCl})$, therefore, the separation factor (S) with respect to the ratio of the diffusion coefficient between the acid and the salt $\left(\mathrm{S}=\mathrm{U}_{\mathrm{H}+} / \mathrm{U}_{\mathrm{Fe} 2+}\right)$ decreased from 60.5 to 40.1 . It is noted that the commercial DF-120 membrane has a corresponding values of $0.0085 \mathrm{~m} \cdot \mathrm{h}^{-1}$ and 18.5 at the same conditions [6]. Therefore, MTz-PPO-5 herein shows great improvement in the diffusion dialysis compared with DF-120 membrane, this results is satisfied and are in agreement with our assumption.

\section{Conclusion}

In summary, a facile one-step reaction for the fabrication of MTz-PPO AEMs with high diffusion dialysis has been developed. The prepared AEMs bearing methylthiazolium as ion exchange groups show high ion exchange capacity, proper water uptake, good swelling and thermal stabilities. The acid diffusion coefficient $(U)$ and separation factor of the optimal AEM were $0.019 \mathrm{~m} \cdot \mathrm{h}^{-1}$ and 40.1 at $25^{\circ} \mathrm{C}$, respectively, when being employed in the diffusion dialysis test from the simulated acidic waste solution. In one word, the satisfied diffusion dialysis performance of the obtained AEMs prepared from a low cost strategy can allow the practical application in acid recovery. For instance, the optimal membrane herein can be used for the acid recovery from the industrial waste water, such as metal etching, titanium white production, and stripping processes and so on.

\section{Acknowledgements}

This project was supported in part by the Jiangsu province " 333 " Engineering 
and Jiangsu province "Qinglan” Engineering.

\section{Conflicts of Interest}

The authors declare no conflicts of interest regarding the publication of this paper.

\section{References}

[1] Rocchetti, L., Vegliò, F., Kopacek, B. and Beolchini, F. (2013) Environmental Impact Assessment of Hydrometallurgical Processes for Metal Recovery from WEEE Residues Using a Portable Prototype Plant. Environmental Science \& Technology, 47, 1581-1588. https://doi.org/10.1021/es302192t

[2] Sahu, S., Sahu, K. and Pandey, B. (2006) Leaching of Zinc Sulfide Concentrate from the Ganesh-Himal Deposit of Nepal. Metallurgical and Materials Transactions B, 37, 541-549. https://doi.org/10.1007/s11663-006-0037-4

[3] Kumari, A., Sinha, M.K., Sahu, S.K. and Pandey, B.D. Investigation of a Novel Ionic Liquid, Cyphos IL 104 for the Solvent Extraction of Mineral Acids. Hydrometallurgy.

[4] Dean, J.G., Bosqui, F.L. and Lanouette, K.H. (1972) Removing Heavy Metals from Waste Water. Environmental Science \& Technology, 6, 518-522. https://doi.org/10.1021/es60065a006

[5] Bramer, H.C. (1971) Pollution Control in the Steel Industry. Environmental Science \& Technology, 5, 1004-1008. https://doi.org/10.1021/es60057a002

[6] Luo, J., WU, C., WU, Y. and Xu, T. (2010) Diffusion Dialysis of Hydrochloride Acid at Different Temperatures Using PPO-SiO2 Hybrid Anion Exchange Membranes. Journal of Membrane Science, 347, 240-249. https://doi.org/10.1016/j.memsci.2009.10.029

[7] Regel-Rosocka, M. (2010) A Review on Methods of Regeneration of Spent Pickling Solutions from Steel Processing. Journal of Hazardous Materials, 177, 57-69. https://doi.org/10.1016/j.jhazmat.2009.12.043

[8] Luo, J., Wu, C., Xu, T. and Wu, Y. (2011) Diffusion Dialysis-Concept, Principle and Applications. Journal of Membrane Science, 366, 1-16. https://doi.org/10.1016/j.memsci.2010.10.028

[9] Oh, S.J., Moon, S.-H. and Davis, T. (2000) Effects of Metal Ions on Diffusion Dialysis of Inorganic Acids. Journal of Membrane Science, 169, 95-105. https://doi.org/10.1016/S0376-7388(99)00333-6

[10] Gohil, G.S., Nagarale, R.K., Binsu, V.V. and Shahi, V.K. (2006) Preparation and Characterization of Monovalent Cation Selective Sulfonated Poly(ether ether ketone) and Poly(ether sulfone) Composite Membranes. Journal of Colloid and Interface Science, 298, 845-853. https://doi.org/10.1016/j.jcis.2005.12.069

[11] Xu, T., Liu, Z., Li, Y. and Yang, W. (2008) Preparation and Characterization of Type II Anion Exchange Membranes from Poly(2,6-dimethyl-1,4-phenylene oxide) (PPO). Journal of Membrane Science, 320, 232-239. https://doi.org/10.1016/j.memsci.2008.04.006

[12] Kumar, G.G., Kim, P., Kim, A.R., Nahm, K.S. and Elizabeth, R.N. (2009) Structural, Thermal and Ion Transport Studies of Different Particle Size Nanocomposite Fillers Incorporated PVdF-HFP Hybrid Membranes. Materials Chemistry and Physics, 115, 40-46. https://doi.org/10.1016/j.matchemphys.2008.11.023 
[13] Afsar, N.U., Erigene, B., Irfan, M., et al. (2018) High Performance Anion Exchange Membrane with Proton Transport Pathways for Diffusion Dialysis. Separation and Purification Technology, 193, 11-20. https://doi.org/10.1016/j.seppur.2017.10.062

[14] Irfan, M., Afsar, N.U., Bakangura, E., et al. (2017) Development of Novel PVA-QUDAP Based Anion Exchange Membranes for Diffusion Dialysis and Theoretical Analysis Therein. Separation and Purification Technology, 178, 269-278. https://doi.org/10.1016/j.seppur.2017.01.051

[15] Mondal, A.N., Cheng, C., Khan, M.I., et al. (2017) Improved Acid Recovery Performance by Novel Poly(DMAEM-co- $\gamma$-MPS) Anion Exchange Membrane via Diffusion Dialysis. Journal of Membrane Science, 525, 163-174. https://doi.org/10.1016/j.memsci.2016.10.042

[16] Lin, X., Wu, L., Liu, Y., et al. (2012) Alkali Resistant and Conductive Guanidinium-Based Anion-Exchange Membranes for Alkaline Polymer Electrolyte Fuel Cells. Journal of Power Sources, 217, 373-380. https://doi.org/10.1016/j.jpowsour.2012.05.062

[17] Sundaraganesan, N., Saleem, H., Mohan, S., Ramalingam, M. and Sethuraman, V. (2005) FTIR, FT-Raman Spectra and $A b$ initio DFT Vibrational Analysis of 2-bromo-4-methyl-phenylamine. Spectrochimica Acta Part A: Molecular and Biomolecular Spectroscopy, 62, 740-751. https://doi.org/10.1016/j.saa.2005.02.043

[18] Huang, L., He, Y., Jin, L., Hou, X., Miao, L. and Lü, C. (2018) Fabrication and Properties of Graphene Oxide/Sulfonated Polyethersulfone Layer-by-Layer Assembled Polyester Fiber Composite Proton Exchange Membranes. Chemical Research in Chinese Universities, 34, 318-325. https://doi.org/10.1007/s40242-018-7313-0

[19] Lin, X., Varcoe, J.R., Poynton, S.D., et al. (2013) Alkaline Polymer Electrolytes Containing Pendant Dimethylimidazolium Groups for Alkaline Membrane Fuel Cells. Journal of Materials Chemistry A, 1, 7262-7269. https://doi.org/10.1039/c3ta10308k

[20] He, Y., Pan, J., Wu, L., Ge, L. and Xu, T. (2015) Facile Preparation of 1,8-Diazabicyclo[5.4.0]undec-7-ene Based High Performance Anion Exchange Membranes for Diffusion Dialysis Applications. Journal of Membrane Science, 491, 45-52. https://doi.org/10.1016/j.memsci.2015.04.055

[21] Ran, J., Wu, L., Lin, X., Jiang, L. and Xu, T. (2012) Synthesis of Soluble Copolymers Bearing Ionic Graft for Alkaline Anion Exchange Membrane. RSC Advances, 2, 4250-4257. https://doi.org/10.1039/c2ra20336g

[22] Lin, X., Liang, X., Poynton, S.D., et al. (2013) Novel Alkaline Anion Exchange Membranes Containing Pendant Benzimidazolium Groups for Alkaline Fuel Cells. Journal of Membrane Science, 443, 193-200. https://doi.org/10.1016/j.memsci.2013.04.059 